\title{
Functional analyses of PAU genes in Saccharomyces cerevisiae
}

Correspondence

Hennie J. J. van Vuuren

hjjvv@interchange.ubc.ca

Received 8 May 2009

Revised 27 July 2009

Accepted 15 September 2009

\author{
Zongli Luo and Hennie J. J. van Vuuren
}

Wine Research Centre, Faculty of Land and Food Systems, University of British Columbia, Vancouver, BC, V6T 1Z4, Canada

\begin{abstract}
PAU genes constitute the largest gene family in Saccharomyces cerevisiae, with 24 members mostly located in the subtelomeric regions of chromosomes. Little information is available about $P A U$ genes, other than expression data for some members. In this study, we systematically compared the sequences of all 24 members, examined the expression of PAU3, PAU5, DAN2, $P A U 17$ and $P A U 20$ in response to stresses, and investigated the stability of all Pau proteins. The chromosomal localization, synteny and sequence analyses revealed that $P A U$ genes could have been amplified by segmental and retroposition duplication through mechanisms of chromosomal end translocation and Ty-associated recombination. The coding sequences diverged through nucleotide substitution and insertion/deletion of one to four codons, thus causing changes in amino acids, truncation or extension of Pau proteins. Pairwise comparison of non-coding regions revealed little homology in flanking sequences of some members. All 24 PAU promoters contain a TATA box, and 22 PAU promoters contain at least one copy of the anaerobic response element and the aerobic repression motif. Differential expression was observed among PAU3, PAU5, PAU17, PAU20 and DAN2 in response to stress, with PAU5 having the highest capacity to be induced by anaerobic conditions, low temperature and wine fermentations. Furthermore, Pau proteins with 124 aa were less stable than those with 120 or 122 aa. Our results indicate that duplicated $P A U$ genes have been evolving, and the individual Pau proteins might possess specific roles for the adaptation of $S$. cerevisiae to certain environmental stresses.
\end{abstract}

\section{INTRODUCTION}

$P A U$ genes are the largest gene family in Saccharomyces cerevisiae. The first $P A U$ gene, $P A U 1$, was isolated by accident and placed into the PAU gene family by sequence analysis and chromo-blotting (Viswanathan et al., 1994). With the availability of complete genome sequences of S. cerevisiae strain S288C, 23 PAU members were initially identified (Goffeau et al., 1996). An additional member was later revealed by comparative genome sequence analysis between S. cerevisiae and other yeast species (Blandin et al., 2000), which finally brought the total number of $P A U$ genes to 24. Among the $24 P A U$ genes, 15 members, YAL068C, YBL108C-A, YDR542W, YGL261C, YGR294W, YHL046C, YIL176C, YIR041W, YKL224C, YLL025W, YLL064C, YMR325W, YOL161C, YOR394W and YPL282C, have not officially been annotated, and their names were only recently reserved in the Saccharomyces Genome Database (SGD) as PAU8-PAU22.

$P A U$ genes usually encode almost identical proteins of 120 124 aa. Due to high sequence homology, functional analysis of such a complex family has been challenging.

Abbreviations: PGK, 3-phosphoglycerate kinase; SGD, Saccharomyces Genome Database; TAP, tandem affinity purification.
Nevertheless, the induction of the expression of some $P A U$ genes by a range of environmental factors has been reported (Rachidi et al., 2000; Davies \& Rine, 2006; Abramova et al., 2001b; Homma et al., 2003; Sahara et al., 2002). The observations that $P A U$ genes are highly upregulated during early stages of wine fermentation (Rossignol et al., 2003; Marks et al., 2008) and that the intracellular concentration of Pau5p is regulated by winemaking stress (Luo \& van Vuuren, 2008) suggest that PAU genes play roles in the adaptation of yeast cells to stress during alcoholic fermentations. Furthermore, Pau proteins are homologous to N-terminal sequences of Tir/Dan proteins, which have a C-terminal putative glycophospholipid (GPI) attachment signal. Tir/Dan proteins might play a role in maintaining cell wall integrity or sterol uptake during stress (Abramova et al., 2001a; Alimardani et al., 2004).

Most of the PAU genes are located in the subtelomeric region of chromosomes, a place for maintaining gene families that serve adaptive purposes (Fabre et al., 2005). Subtelomeric regions have been evolving more quickly than the rest of the genome (Kellis et al., 2003). The other large subtelomeric gene family in $S$. cerevisiae is the DUP gene family, which has 23 members. DUP gene duplication 
is thought to have occurred through non-reciprocal translocation, tandem duplication and transposon $\mathrm{Ty}$ associated duplication (Despons et al., 2006). Gene duplication has long been considered a major force driving evolution (Ohno, 1970), and may occur via three mechanisms: chromosomal or segmental duplication, retroposition and tandem duplication (Zhang, 2003; Kong et al., 2007; Pan \& Zhang, 2008). The duplicated genes may either be lost or gain novel functions to retain their existence through divergence of sequence and expression during evolution (Taylor \& Raes, 2004; Lynch \& Conery, 2000). Systematic analyses at the genome level have shown that a large proportion of duplicated genes in yeast have diverged rapidly, and the vast majority of gene pairs eventually become divergent in sequence and expression ( $\mathrm{Gu}$ et al., 2002). How so many PAU genes originated, why they were preserved and evolved, and their specific roles, are still unknown.

With these questions in mind, we systematically compared the regulatory and coding sequences of all 24 members, analysed induction of PAU3, PAU5, DAN2, PAU17 and $P A U 20$ in response to a range of environmental factors, and characterized the stability of 17 Pau proteins. We observed that $P A U$ genes might have originated from TIR/ $D A N$ genes, been amplified through Ty-associated recombination and chromosomal end translocation, and diverged in sequence, stress response and protein stability.

\section{METHODS}

Sequence analyses. Sequences were derived from the SGD (http:// www.yeastgenome.org). The alignment method was CLUSTAL $\mathrm{w}$ in TCOFFEE (Notredame et al., 2000) v.5.05 or MEGA 3.1 (Kumar et al., 2004). The program was run using default options. The output was viewed with Jalview and inspected visually. A phylogenetic tree (neighbour-joining method) was established with MEGA 3.1. The similarity of sequences was examined using BLASTN2.2.21 + (Altschul et al., 1997). The YEASTRACT database (Teixeira et al., 2006) was searched for DNA motifs in promoter regions.

Yeast strains and culture conditions. S. cerevisiae strain BY4742

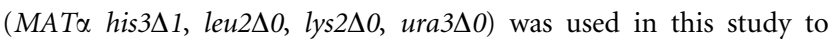
amplify the $P A U$ genes, and to construct strains that encode tandem affinity purification (TAP) sequences or TAP-tagged Pau proteins in the genome (Table 1) or on plasmids. A wild-type diploid wine yeast strain $\mathrm{S} 92$ was also used for amplification of the PAU7, PAU9 and $P A U 21 / 22$ genes, and for expression of TAP-tagged genes and wine fermentation. All yeast strains were grown in Difco yeast extractpeptone-dextrose (YPD; $1 \%$ yeast extract, $2 \%$ peptone, $2 \%$ glucose) or minimal medium [0.67\% Difco yeast nitrogen base (YNB), $2 \%$ glucose plus the required amino acids]. For stress induction, cells were grown aerobically in YPD at $25{ }^{\circ} \mathrm{C}$ to mid-exponential phase, centrifuged, washed with sterilized water, and then resuspended in YPD, YNB (without a carbohydrate, amino acids and ammonium sulphate for combination of nitrogen and carbohydrate starvation stress), YNB plus $2 \%$ glucose (for nitrogen starvation stress), YNB plus amino acid and ammonium sulphate (for carbohydrate starvation stress), or YNB plus $2 \%$ galactose. Cells were then grown aerobically at $25{ }^{\circ} \mathrm{C}$ for $2 \mathrm{~h}$ or $10{ }^{\circ} \mathrm{C}$ for $24 \mathrm{~h}$. To study Pau-TAP induction during anaerobic growth, cells were grown in $5 \mathrm{ml} \mathrm{YPD}$ in a tightly capped $5 \mathrm{ml}$ tube without shaking at $25^{\circ} \mathrm{C}$. Anaerobic
Table 1. Yeast strains used in this study

\begin{tabular}{|c|c|c|}
\hline Strain & Genotype & Source \\
\hline BY4742 & 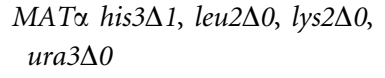 & Invitrogen \\
\hline LY5 & BY4742, PAU3-TAP-URA3 & This study \\
\hline LY6 & BY4742, PAU5-TAP-URA3 & This study \\
\hline LY7 & BY4742, PAU17-TAP-URA3 & This study \\
\hline LY8 & BY4742, PAU20-TAP-URA3 & This study \\
\hline LY9 & BY4742, DAN2-TAP-URA3 & This study \\
\hline LY19 & BY4742, pau5:: TAP-KanMX4 & This study \\
\hline LY20 & BY4742, pau3:: TAP-KanMX4 & This study \\
\hline LY280 & BY4742, pau17:: TAP-URA3 & This study \\
\hline LY281 & BY4742, pau20:: TAP-URA3 & This study \\
\hline LY282 & BY4742, dan2:: TAP-URA3 & This study \\
\hline S92 & $M A T \alpha / a$ & BioSpringer USA \\
\hline LY12-7 & S92, PAU3-TAP-KanMX4 & This study \\
\hline LY15-8 & S92, PAU5-TAP-KanMX4 & This study \\
\hline LY21-7 & S92, DAN2-TAP-KanMX4 & This study \\
\hline LY22-8 & S92, PAU17-TAP-KanMX4 & This study \\
\hline LY23-8 & S92, PAU20-TAP-KanMX4 & This study \\
\hline
\end{tabular}

conditions for testing the activity of the $P A U$ promoters were obtained using BBL GasPak anaerobic systems (Becton Dickinson).

TAP tagging and plasmids. Genome TAP tagging was performed as described previously (Luo \& van Vuuren, 2008), and the oligonucleotides used for tagging are listed in Table 2. The following plasmids were constructed: (1) pUG36-PAU5. The coding region of the PAU5 gene was amplified with primers p89 and p148 from genomic DNA of strain BY4742, digested with SpeI and XhoI, and then cloned into SpeI-XhoI sites of pUG36. (2) pUG36-PAU7 (B) and pUG36-PAU7 (S). Due to the high degree of sequence homology with some of the other PAU genes, the coding sequence of PAU7 cannot be amplified directly by one round of PCR. We therefore first amplified the specific sequences covering the PAU7 ORF by using primers p89 and p141 from laboratory strain BY4742 and wine strain S92, respectively. The PAU7 coding sequence was then amplified from the first-round PCR products with primers $\mathrm{p} 89$ and p151. After digestion with SpeI and XhoI, the PCR products were cloned into SpeI-XhoI sites of pUG36, yielding pUG36-PAU7 (B) (B refers to the PAU7 coding sequence from strain BY4742) and pUG36-PAU7 (S) (S refers to the PAU7 coding sequence from strain S92). (3) pUG36-PAU9. For the same reason as above, a two-round PCR strategy was used to clone the PAU9 ORF. The first round was carried out using primers p142 and p143 from BY4742 and primers for the second-round PCR were p89 and p151. The PCR products were trimmed by SpeI and XhoI, and inserted into pUG36 pre-digested with the same enzymes. (4) pPAU21/22-TAP, pPAU21/22 (M1I)-TAP and pPAU21/22 (M41I)TAP. The entire $P A U 21 / 22$ coding sequence plus their identical 1018 bp promoter sequence was amplified by primers p146 and p147 from genomic DNA extracted from BY4742. After digestion with XbaI and $X h o I$, the fragment was ligated into the SpeI and XhoI sites of pKS, yielding plasmid pKS-PAU21/22, on which the mutated PAU21/ 22 gene encoding either the M1I or the M41I substitution was generated by site-directed mutagenesis using a QuickChange mutagenesis kit (Stratagene). After the mutation was confirmed by DNA sequencing, an $X b a I-X h o I$ fragment of the wild-type and the mutated PAU21/22 gene was inserted into the same sites of pRS326, yielding pRS326-PAU21/22, pRS326-PAU21/22 (M1I) and pRS326PAU21/22 (M41I). Subsequently the TAP tag plus CYC1 termination sequences were cut from plasmid pMET25p-TAP (Luo \& van Vuuren, 
Table 2. Oligonucleotides used in this study

\begin{tabular}{|c|c|}
\hline Number and name & Sequence $\left(5^{\prime}-3^{\prime}\right)$ \\
\hline p17. PAU3-up & cagtgctctatctaaggacggtatctacactgctattccaaaatccatggaaaagagaag \\
\hline p18. PAU5-up & ctctagcgctctatccgcagacggtatctacactattgcaaattccatggaaaagagaag \\
\hline p19. DAN2-up & cagcgctctatccaaggacggtatctacactgctgttccaaactccatggaaaagagaag \\
\hline p20. PAU17-up & cagcgctctatctgcagacggtatctacactgctgtaccaaactccatggaaaagagaag \\
\hline p21. PAU20-up & ctccaaggctctatccaaagatggtatctacactatcgcaaactccatggaaaagagaag \\
\hline p22. PAU3-down & cagcactactcattaagaatatatgcaataatactggatagcatacgactcactataggg \\
\hline p23. PAU5-down & ttcctgcctagtgtatttcgtcagggcgaaccttcggataggctacgactcactataggg \\
\hline p24. DAN2-down & aaatcataattatttttatccgttcgtaaagcaatccagtgcttacgactcactataggg \\
\hline p25. PAU17-down & cgaaaccaatttcatttattcataacattctaatactcgtaaatacgactcactataggg \\
\hline p26. PAU20-down & atttgaaatttataatttgctataaatcttggttttcttggtctacgactcactataggg \\
\hline p27. PAU3-f & actctatctccatctgacgaaagg \\
\hline p28. PAU5-f & gtgaccagtaatagcctgtttggg \\
\hline p29. DAN2-f & cagctttgattaactctttccgac \\
\hline p30. PAU17-f & catgcctcgttcaggaacaagtgc \\
\hline p31. PAU20-f & catgcctcgttcaggaacaagtgc \\
\hline p37. TEV-r & caaattctcgctagcagtagttgg \\
\hline p47. TAP_C_XhoI & attgtactcgagtcaggttgacttccccg \\
\hline p89. PAU3_speI & ctgcagactagtatggtcaaattaacttcaatcg \\
\hline p90. DAN2_speI & ctgcagactagtatggtcaaactaacttcaattg \\
\hline p91. PAU2_speI & ctgcagactagtatggtcaaattaacttcaattg \\
\hline p141. PAU7_r & tcgtaaagcagggactctag \\
\hline p142. PAU9_f & tcaggaatgagtaacaaagatg \\
\hline p143. PAU9_r & tcattcgtaaaggcatcactcc \\
\hline p144. PAU21_f & gagaatatgtgaagtgctaaag \\
\hline p145. PAU21_r & tcgttcgtaaaagcttctctc \\
\hline p146. PAU21_XbaI & attgtatctagaaatggggcatttgacac \\
\hline p147. PAU3_XhoI & attgtactcgagttttggaatagcagtgtagatacc \\
\hline p148. PAU5_XhoI & attgtactcgagatttgcaatagtgtagatacc \\
\hline p149. DAN2_XhoI & attgtactcgaggtttggaacagcagtgtagatacc \\
\hline p150. PAU17_Xho1 & attgtactcgaggtttggtacagcagtgtagatacc \\
\hline p151. PAU20_Xho1 & attgtactcgaggtttgcgatagtgtagatacc \\
\hline p153. DAN3_SpeI & ctgcagactagtatggtcaaactaacttcaatcgc \\
\hline p166. PAU21_m1f & cgaatcgtttaagtggtgatcaccaatgaaggaatagg \\
\hline p167. PAU21_m1r & cctattccttcattggtgatcaccacttaaacgattcg \\
\hline p168. PAU21_m2f & ctaacaaacaaaacaaatacaatcgtcaaattaacttcaatcgctgctgg \\
\hline p169. PAU21_m2r & ccagcagcgattgaagttaatttgacgattgtatttgttttgtttgttag \\
\hline p180. PAU2_f & ggtatatgcctccactcttctc \\
\hline p181. PAU2_r & ctaagtttcatagcatttccttcatt \\
\hline p182. PAU4_fc_XbaI & ctgcagtctagaatggtcaaattaacttcaatcgcc \\
\hline p183. PAU4_rc_XhoI & attgtactcgaggtttgcgatagtgtagatacca \\
\hline p184. PAU16_r & gttcgtaaaattggcgtttgtctctaa \\
\hline p185. PAU16_rc_XhoI & attgtactcgagatttgcgatagtgtagatacc \\
\hline p186. PAU10_mf & ccagtgctctatccaaggtcggtatctacactatcg \\
\hline p187. PAU10_mr & cgatagtgtagataccgaccttggatagagcactgg \\
\hline p188. PAU12_mf & ccaatactactctttccaagccgctcatccaactgaaacc \\
\hline p189. PAU12_mr & ggtttcagttggatgagcggcttggaaagagtagtattgg \\
\hline p190. PAU13_rc_XhoI & attgtactcgaggtttgtgatagtgtagataccgtcc \\
\hline p191. PAU15_mf & gtttcaagcagctcatccaagtgagacctacccagttgag \\
\hline p192. PAU15_mr & ctcaactgggtaggtctcacttggatgagctgcttgaaac \\
\hline
\end{tabular}

2008) by SalI and KpnI and ligated to the XhoI-KpnI sites of pRS326PAU21/22, pRS326-PAU21/22 (M1I) and pRS326-PAU21/22 (M41I), yielding $\mathrm{p} P A U 21 / 22$-TAP, $\mathrm{p} P A U 21 / 22$ (M1I)-TAP and $\mathrm{p} P A U 21 / 22$ (M41I)-TAP, respectively. (5) Pau-TAP expression plasmids. To generate plasmids containing the Pau-TAP fusion expression cassette under the control of the MET25 promoter, the intermediate cloning plasmids were first constructed. The coding sequences of PAU2,
PAU3, PAU4, PAU5, PAU7, PAU9, PAU13, PAU16, PAU17, PAU19, $P A U 20, D A N 2$ and DAN3 were amplified from genomic DNA extracted from BY4742 or existing plasmids, digested with SpeI and $X h o I$, and ligated to the same sites of the cloning vector pKS, yielding pKS-PAU2, pKS-PAU3, pKS-PAU4, pKS-PAU5, pKS-PAU7, pKS$P A U 13$, pKS-PAU16, pKS-PAU17, pKS-PAU19, pKS-PAU20, PKS$D A N 2$ and pKS-DAN3, respectively. pKS-PAU1 was generated by 
ligation of the small EcoRV-NcoI fragment of pKS-PAU20 with the large EcoRV-NcoI fragment of pKS-PAU9. pKS-PAU6 was generated by ligation of the small $X b a \mathrm{I}-\mathrm{NcoI}$ fragment of pKS-PAU9 with the large XbaI-NcoI fragment of pKS-PAU20. Plasmids pKS-PAU10, pKS-PAU15 and pKS-PAU12 were derived by site-directed mutagenesis of plasmids pKS-PAU9, pKS-PAU19 and pKS-DAN3, respectively, based on only one amino acid difference between these pairs of Pau proteins. After DNA sequencing, the correct PAU ORFs were cut from their intermediate cloning plasmids with $X b a \mathrm{I}$ and $X h o \mathrm{I}$ and inserted into vector pMET25p-TAP pre-digested with the same restriction enzymes, yielding the following plasmids which encode different TAP-fused Pau proteins driven by the MET25 promoter: pMET25p-PAU1-TAP, pMET25p-PAU2-TAP, pMET25p-PAU3-TAP, pMET25p-PAU4-TAP, pMET25p-PAU5-TAP, pMET25p-PAU6-TAP, pMET25p-PAU7-TAP, pMET25p-PAU9-TAP, pMET25p-PAU10TAP, pMET25p-PAU12-TAP, pMET25p-PAU13-TAP, pMET25pPAU15-TAP, PMET25p-PAU16-TAP, pMET25p-PAU17-TAP, pMET25p-PAU19-TAP, pMET25p-PAU20-TAP, pMET25p-DAN2TAP and pMET25p-DAN3-TAP. All DNA manipulations were performed by standard procedures as described by Ausubel et al. (1999), and oligonucleotide sequences used for cloning are shown in Table 2.

Protein extraction and Western blot analyses. Whole-cell extracts were prepared and subjected to SDS-PAGE and immunoblotting as described previously (Luo \& van Vuuren, 2008). A monoclonal anti-GFP antibody (Roche) was used to detect GFPfusion proteins. Peroxidase-anti-peroxidase soluble complex (PAP; Sigma) was used to detect TAP or TAP-tagged proteins. As a loading control, Pgklp was also detected in the blots using monoclonal anti3-phosphoglycerate kinase (anti-PGK) antibody (Molecular Probes).

Cycloheximide chase assay. For aerobic chasing, yeast strains transformed with pMET25p-PAU1-TAP and pMET25p-PAU3-TAP were grown aerobically at $25{ }^{\circ} \mathrm{C}$ to mid-exponential phase in YNB plus essential nutrients. After addition of cycloheximide to a final concentration of $100 \mu \mathrm{g} \mathrm{ml}^{-1}$, the cell culture was chased for 10,15 , 30 and $40 \mathrm{~min}$, respectively. For anaerobic chasing, cells were grown in a $50 \mathrm{ml}$ bottle filled with $40 \mathrm{ml}$ YNB plus essential nutrients and fitted with an S-shaped air lock. When the cell density reached an $\mathrm{OD}_{600} 0.5$, cycloheximide at a final concentration of $100 \mu \mathrm{g} \mathrm{ml}^{-1}$ was injected through the rubber stopper to the culture. After addition of cycloheximide, the culture was kept under anaerobic conditions, and samples were withdrawn using syringes at 10, 15, 30 and $40 \mathrm{~min}$. Equal volumes of cells $\left(1 \mathrm{OD}_{600}\right)$ were collected, added to $10 \mathrm{mM}$ $\mathrm{NaN}_{3}$ and incubated on ice for $10 \mathrm{~min}$. Cell lysis and immunoblotting were performed as previously described (Luo \& van Vuuren, 2008).

\section{RESULTS AND DISCUSSION}

\section{Expansion of PAU genes in S. cerevisiae}

There are 24 PAU genes in S. cerevisiae distributed across all 16 chromosomes; 19 copies are located in subtelomeric regions, and five copies are found in internal regions (Fig. 1). Using the synteny viewer in SGD, four $P A U$ genes (PAU2, PAU11, PAU12 and DAN2) were detected in Saccharomyces bayanus, five (PAU2, PAU7, PAU9, PAU11 and PAU17) in Saccharomyces mikatae and five (PAU2, PAU7, PAU9, PAU21 and DAN3) in Saccharomyces paradoxus, far fewer than the 24 copies in S. cerevisiae. We also searched for PAU orthologues in the genomes of ancient yeast species that existed before whole-genome duplication through the yeast gene order browser (YGOB) (Byrne \& Wolfe, 2006), and only found TIR/DAN genes, with $5^{\prime}$ end sequences that are highly similar to $P A U$ genes. This observation raised the possibility that $P A U$ genes originated from the $\mathrm{N}$-terminal sequence of TIR/DAN genes. Inspection of the gene order and the synteny around all $P A U$ genes in $S$. cerevisiae revealed some clues about how $P A U$ genes expanded. Four of the five internal $P A U$ genes (PAU2, PAU5, PAU17 and DAN2) are flanked by a transposable element (Ty1) at one end, suggesting that they were integrated into the region by recombination between transposable elements. The other internal $P A U$ gene, $P A U 7$, is located adjacent to a transposition hot-spot where one solo and five tandem repeats from the DUP240 family are located (Wirth et al., 2005). It is interesting that all subtelomeric paralogues of $P A U$ genes are in the same orientation relative to the telomere: genes close to the left end of chromosomes are located on the Crick strand, and genes close to the right end of chromosomes are on the Watson strand (Fig. 1). This same orientation implies that they might have been duplicated by chromosome end translocation. The reason why so many $P A U$ genes have evolved remains a mystery. It has been proposed that subtelomeric regions are preferred sites for efficient amplification of useful genes, the expression of which gives yeast cells advantages to adapt to environmental changes (Fabre et al., 2005). For example, it has been proposed that the SUC, MAL and MEL families were amplified in subtelomeric regions for yeast to use specific carbon sources (Pryde et al., 1997). Given that S. cerevisiae is the main natural species used to ferment grape must to produce wine, and that the expression of $P A U$ genes is induced during wine fermentation, the expansion of $P A U$ genes in the subtelomeric region of $S$. cerevisiae could contribute to its adaptation to wine fermentation stress.

\section{Sequence divergence in the coding region of PAU genes}

During its evolution, S. cerevisiae has evolved mechanisms, such as sequence specialization, to acquire novel functions for duplicated genes. Although the exact role of $P A U$ genes remains unclear, it is worthwhile to detect the sequence variation amongst the $P A U$ members. The sequence alignment of $P A U$ genes and Pau proteins was therefore performed using MEGA 3.1 (Kumar et al., 2004) (Figs 2 and 3); $100 \%$ identity was shown within the following pairs: PAU1/PAU14, PAU6/PAU18, and PAU21/PAU22. These pairs were located within the duplicated segments at the chromosome ends, which share high sequence similarity (above $90 \%$ ). Insertion or deletion of one to four codons was found to be the reason for length polymorphism of Pau proteins whose lengths are 120,122, 123 or 124 aa (Fig. 3). A single-nucleotide substitution or insertion was observed to cause the truncation of Pau7p (55 aa) and Pau9p (42 aa), and the extension of Pau21/22p (164 aa). These mutations could be systematic sequencing errors as reported for other genes in SGD. The most frequently occurring mutations are 


\begin{tabular}{|c|c|c|c|c|}
\hline \multirow{2}{*}{ ORF/NAME } & \multicolumn{2}{|c|}{ ORF length } & \multirow{2}{*}{\multicolumn{2}{|c|}{ Chromosomal location (distance $(\mathrm{kb})$ from the telomere end) }} \\
\hline & nt (bp) & AA & & \\
\hline YAL068C/PAU8 & 363 & 120 & subtelomeric & $\leftrightarrow$ \\
\hline YAR020C/PAU7 & 168 & 55 & Chr I (53.1), & $\rightarrow+$ \\
\hline YBL108C-A/PAU9 & 129 & 42 & Chr II (7.7), $\quad$ subtelomeric & $\longmapsto$ \\
\hline YBR301W/DAN3 & 363 & 120 & Chr II (4.1), subtelomeric & $\longrightarrow$ \\
\hline YCR104W/PAU3 & 375 & 124 & Chr III (8.8), subtelomeric & $\rightarrow \longrightarrow$ \\
\hline YDR542W/PAU10 & 363 & 120 & Chr IV (8.6), $\quad$ subtelomeric & $\longrightarrow$ \\
\hline YEL049W/PAU2 & 363 & 120 & Chr V (63.7), & + \\
\hline YFL020C/PAU5 & 369 & 122 & Chr VI (99.5), & + \\
\hline YGL261C/PAU11 & 363 & 120 & Chr VII (6.6), $\quad$ subtelomeric & $\longleftarrow$ \\
\hline YGR294W/PAU12 & 363 & 120 & Chr VII (10.6), subtelomeric & $\longrightarrow$ \\
\hline YHL046C/PAU13 & 363 & 120 & Chr VIII (12.2), subtelomeric & + \\
\hline YIL176C/PAU14 & 363 & 120 & Chr IX (9.1), subtelomeric & $\longmapsto$ \\
\hline YIR041W/PAU15 & 375 & 124 & Chr IX (5.9), $\quad$ subtelomeric & $\longrightarrow$ \\
\hline YJL223C/PAU1 & 363 & 120 & Chr $\times(9.1), \quad$ subtelomeric & $\longmapsto$ \\
\hline YKL224C/PAU16 & 372 & 123 & Chr XI (2.1), $\quad$ subtelomeric & $\longmapsto$ \\
\hline YLL025W/PAU17 & 375 & 124 & Chr XII (94.7), & ⺊ \\
\hline YLL064C/PAU18 & 363 & 120 & Chr XII (13.4), subtelomeric & $+\infty$ \\
\hline YLR037C/DAN2 & 375 & 124 & Chr XII (855.1), $\quad$ internal & $\rightarrow+$ \\
\hline YLR461W/PAU4 & 363 & 120 & Chr XII (15.2), subtelomeric & $\rightarrow$ \\
\hline YMR325W/PAU19 & 375 & 124 & Chr XIII (1.7), subtelomeric & $\longrightarrow$ \\
\hline YNR076W/PAU6 & 363 & 120 & Chr XIV (2.4), subtelomeric & $\longrightarrow$ \\
\hline YOL161C/PAU20 & 363 & 120 & Chr XV (11.9), subtelomeric & $\longmapsto$ \\
\hline YOR394W/PAU21 & 495 & 164 & Chr XV (8.5), subtelomeric & $\longrightarrow$ \\
\hline YPL282C/PAU22 & 495 & 164 & Chr XVI (8.4), subtelomeric & $\longmapsto$ \\
\hline
\end{tabular}

Fig. 1. Chromosomal location of $P A U$ genes in $S$. cerevisiae strain $\mathrm{S} 288 \mathrm{C}$. The number in parentheses indicates the distance (in $\mathrm{kb}$ ) of the $P A U$ gene from the telomere end. Subtelomeric regions were defined by a distance of less than $20 \mathrm{~kb}$ from each telomere end (Wyrick et al., 1999). AA, amino acid; vertical lines indicate the relative location of PAU genes on the chromosomes; the filled circle represents the centromere.

nucleotide substitutions. Synonymous single-nucleotide changes outnumber non-synonymous changes. A strong preference for $\mathrm{C} / \mathrm{T}$ transition at the third place of the triplet codon was also observed. For example, compared with the consensus sequence, PAU5 showed 48 nucleotide variations, of which $28(58.3 \%)$ were $\mathrm{C} / \mathrm{T}$ transitions that do not change the amino acid sequence. This preference might explain why $P A U$ genes exhibit highly biased codon usage: among 122 codons of PAU5, 87 contain $\mathrm{C}$ or $\mathrm{T}$ in the third position. Thus, $P A U$ genes seem to have evolved with selection pressure to maintain their protein sequences.

\section{Revisiting the sequences of PAU7, PAU9 and PAU21/22}

Given that some errors have been reported in the SGD sequence data, we reasoned that the single-nucleotide mutations which lead to truncation of Pau7p and Pau9p, and extension of Pau21/22p (Fig. 4a), might be due to sequencing errors. To test this, we amplified and sequenced PAU7, PAU9 and PAU21/22 from an S288C-derivative strain, BY4742, and a wine yeast strain of $S$. cerevisiae, S92 (Fig. 4b). In BY4742, in the sequence of PAU7, the nucleotide at position 166 is thymidine $(\mathrm{T})$, confirming the reference sequence. However, PAU7 in the wine yeast strain S92 has a cytidine (C) rather than a thymidine (T) at position 166, extending Pau7p in S92 to 122 aa, the same size as Pau7p in the relatively ancient species $S$. paradoxus and S. mikatae. The PAU9 gene amplified from both BY4742 and S92 has two Ts starting at the -180 position rather than three Ts as reported in the reference sequence (Fig. 4b), suggesting a sequencing error in PAU9 in the reference sequence. As a consequence, the corresponding Pau9p is corrected to 120 aa long, thus sharing an identical 


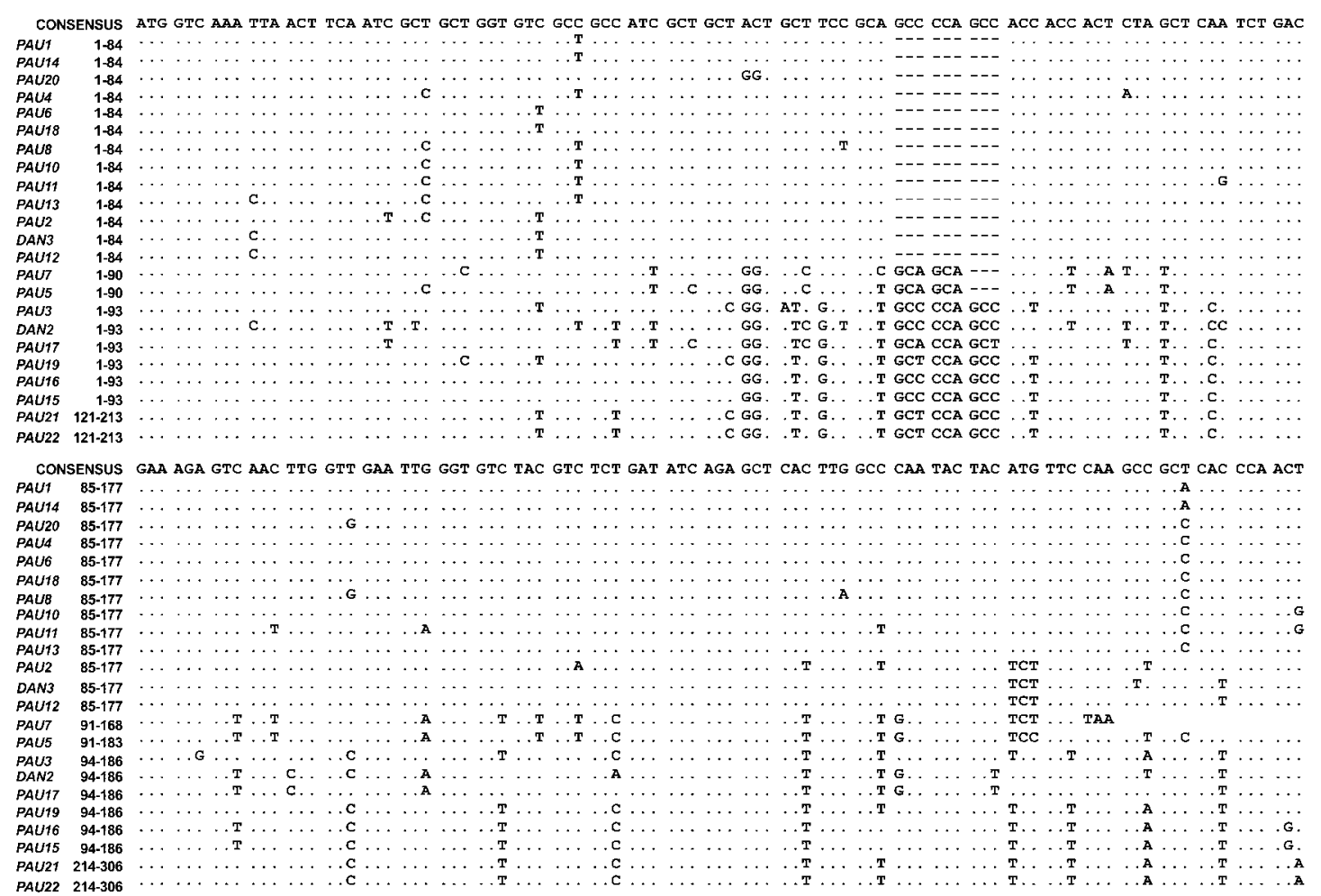

CONSENSUS GAA ACC TAC CCA GTT GAA GTT GCT GAA GCC GTT TTC AAC TAC GGT GAC TTC ACC ACC ATg TTG ACT GGT ATT GCC CCA GAC CAA GTG ACC AGA PAU1 178.22 $\begin{array}{lll}\text { PAU14 } & 178-270 \\ \text { PAU20 } & 178-270\end{array}$

$\begin{array}{lll}\text { PAU4 } & 178-270 \\ \text { PAU6 } & 178-270\end{array}$

$\begin{array}{ll}\text { PAU6 } & 178-270 \\ \text { PAU18 } & 178-270\end{array}$

$\begin{array}{lll}\text { PAUUS } & 178-270 \\ \text { PAUS } & 17-36 \\ \text { PAUS } & 178-270\end{array}$

$\begin{array}{ll}\text { PAU10 } & 178-270 \\ \text { PAUY11 } & 178-270 \\ \text { PAT }\end{array}$

PAU13 $1788-270$

$\begin{array}{ll}\text { PAU2 } & 178-270 \\ \text { DAN3 } & 178-270\end{array}$

$\begin{array}{ll}\text { PAN3 } & 178-270 \\ \text { PAU12 } & \mathbf{1 7 8 - 2 7 0}\end{array}$

PAUS $184-276 \ldots \ldots$.

$\begin{array}{ll}\text { PAU3 } & 187-279 \\ \text { DAN2 } & 187-279\end{array}$

PAU17 187-279

PAU16 $187-279$

$\begin{array}{ll}\text { PAU15 } & 187-279 \\ \text { PAU21 } & 307-399\end{array}$

$\begin{array}{ll}\text { PAU21 } & 307-399 \\ \text { PAU22 } & 307-399\end{array}$

CONSENSUS ATG ATC ACC GGT GTC CCA TGG TAC TCC AGC AGA TTA AAG CCA GCC ATC TCC AGT GCT CTA TCC AAG GAC GGT ATC taC ACT GCT ATC GCA AAC taG PAU1 271-363

PAU14 271-363

PAUL20 271-363

$\begin{array}{ll}\text { PAUU6 } & 271-365 \\ \text { PAU1-365 } & 271.363\end{array}$

PAU18 271-363 $\ldots .$.

$\begin{array}{lr}\text { PAUY } & 37-129 \\ \text { PAUS } & 271-363\end{array}$

\begin{tabular}{ll} 
PAU10 & $271-363$ \\
PAU11 & $271-363$ \\
\hline
\end{tabular}

PAU13 271-363

PAU2 271-363

$\begin{array}{ll}\text { DAN3 } & 272-363 \\ \text { PAU12 } & 271-363\end{array}$

PAUS $277-369$ G. T

DAN2 $280-375 \mathrm{G}$.

PAUT7 280-375 G.

PAU19 280-375 G.

PAU16 $280-372 \mathrm{G}$.

PAU15 280-375 G.T.

PAU21
PAU22
$400-495$ G.C
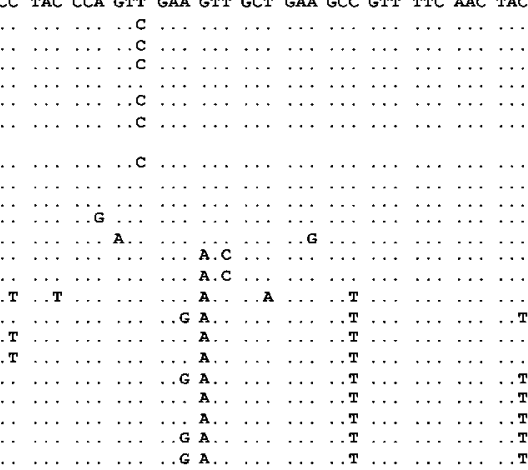
T. T
T. T
T. .
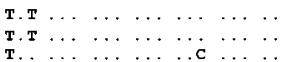

\section{ATG}
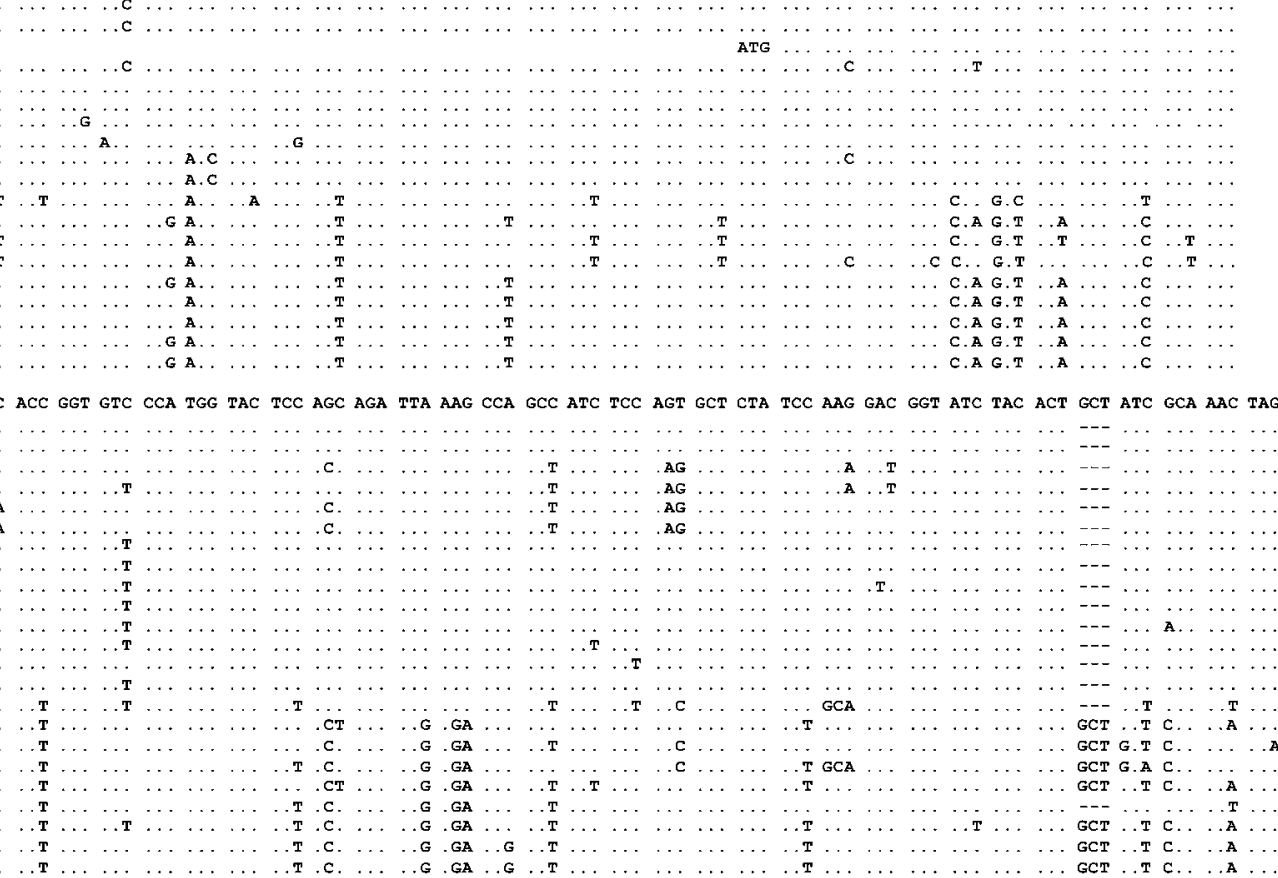

Fig. 2. Alignment of $P A U$ genes created by MEGA 3.1. Dots represent nucleotides identical to the consensus sequence. Hyphens represent the absence of the nucleotide compared with the consensus sequence. The $5^{\prime}$ extended sequences of PAU21/22 compared with other PAU genes are not included. 


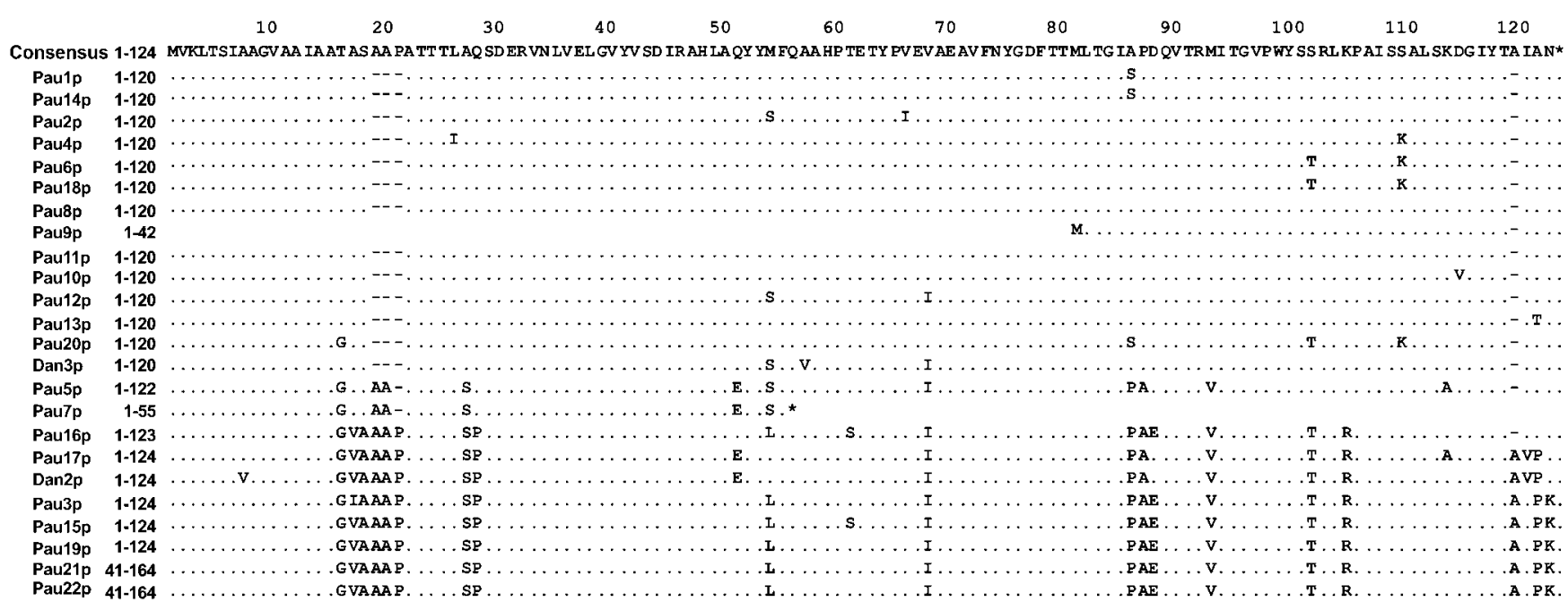

Fig. 3. Alignment of Pau proteins created by MEGA 3.1. Dots represent amino acids identical to the consensus sequence. Hyphens represent the absence of amino acids compared with the consensus sequence. The $\mathrm{N}$-terminal extended sequences of Pau21/22p compared with other Pau proteins are not included.

sequence with Pau8p and Pau11p. These sequencing results were further confirmed by Western blot analyses showing that the molecular masses of GFP-Pau7p and GFP-Pau9 are almost the same as that of GFP-Pau5p (Fig. 4c). The sequences of PAU21/22 in both BY4742 and S92 are the same as the reference sequences (Fig. $4 \mathrm{~b}$ ).

\section{PAU21/22 encodes two peptides}

Pau21/22p contains a 40 aa $\mathrm{N}$-terminal extension compared with other Pau proteins. The PAU21/22 ORF contains three in-frame ATGs, with the second one corresponding to the translational start site of other PAU genes (Fig. 4a). We speculated that $P A U 21 / 22$ produced two peptides of different lengths by translating from different start codons. To test this possibility, we cloned PAU21/22 with their promoter sequence, changed two potential start codons, Met1 and Met41, respectively, to isoleucine, and constructed C-terminal TAP tag-fused expression cassettes in a $2 \mu$ plasmid pRS326. As PAU genes have been reported to be anaerobic genes (Rachidi et al., 2000), we tested the expression of Pau21/22p in anaerobically grown cells. Western blot analysis showed that under the anaerobic conditions, cells expressed wild-type Pau21/22p-TAP as two major proteins (36 and $40 \mathrm{kDa}$ ) (Fig. $4 \mathrm{~d}$, lane 1), mutation of the first ATG of PAU21/22 resulted in the disappearance of the $40 \mathrm{kDa}$ band (Fig. $4 \mathrm{~d}$, lane 2), and mutation of the second ATG at position 121 made the $36 \mathrm{kDa}$ band disappear (Fig. 4d, lane 3), demonstrating that ATGs at both position 1 and position 121 in PAU21/22 are functional and initiate the translation of peptides of 164 and 124 aa, respectively. From the relative amount of the two peptides, the small one of similar size to other Pau proteins is the major form induced by anaerobiosis. Whether the 40 aa extension of Pau21/22p at its $\mathrm{N}$ terminal is function-related remains unknown.

\section{Relationship of PAU genes and their relatives}

Pau proteins share homology with the N-terminal region of Tir and Dan proteins. To establish their genetic relationship, a phylogenetic tree was constructed using MEGA 3.1 for all PAU, DAN and TIR genes in S. cerevisiae (Fig. 5). Our data indicated that $P A U$ genes are clustered into three groups that encode proteins of 120,122 and 123/124 aa. The PAU gene family is more closely related to the DAN family than to the TIR family. DAN2 was clustered in group III of the PAU family and DAN3 in group I of the $P A U$ family; they were obviously misnamed previously (Abramova et al., 2001a). We therefore suggest that DAN2 and DAN3 be renamed as PAU23 and PAU24, respectively.

\section{Comparison of flanking sequences among PAU genes}

To determine potential divergence in the flanking regions of the PAU genes, we retrieved and compared up to $500 \mathrm{bp}$ upstream of the start codon and 500 bp downstream of the stop codon from all 24 PAU genes (Table 3). In general, the similarity varies greatly between the flanking sequences of the PAU genes: from no significant similarity to $100 \%$ identity. Most of the subtelomeric $P A U$ genes showed high homology in the flanking regions, while the internal $P A U$ genes (PAU2, PAU5, PAU7, PAU17 and DAN2) showed no significant similarity, except for PAU5 and PAU7, which had $79 \%$ identity in their $5^{\prime} 500$ bp flanking sequence. Among the higher-homology flanking sequences in all $P A U$ genes, the minimum identity was $66 \%$, lower than that of 
(a)
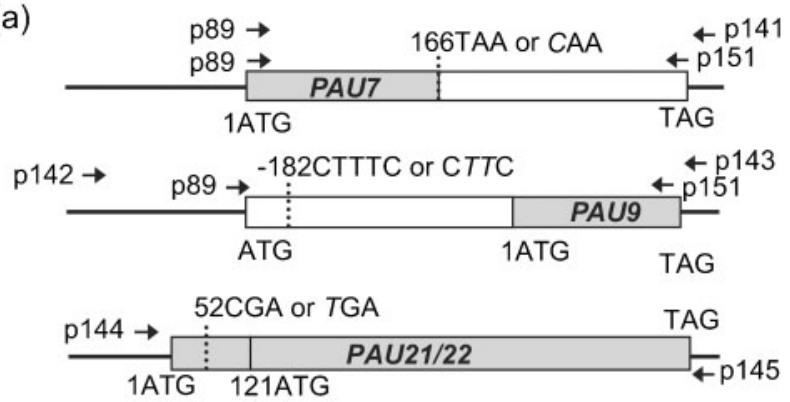

(b)

\begin{tabular}{|l|r|c|c|c|}
\hline \multicolumn{2}{|c|}{ ORFs } & PAU7 & PAU9 & PAU21/22 \\
\hline $\begin{array}{l}\text { Sequences } \\
\text { from this } \\
\text { study }\end{array}$ & BY4742 & 166TAA & -182CTTC & 52CGA \\
\cline { 2 - 5 } & S92 & 166CAA & -182CTTC & 52CGA \\
\hline $\begin{array}{l}\text { Reference } \\
\text { sequences }\end{array}$ & S288C & 166TAA & -182CTTTC & 52CGA \\
\hline
\end{tabular}

(c)

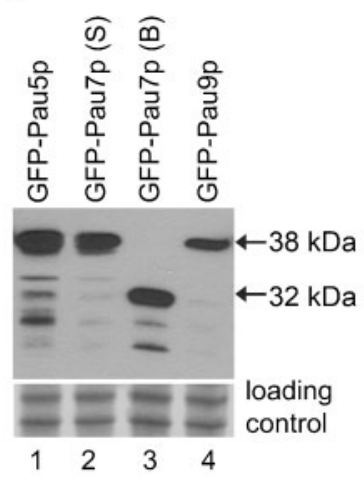

(d)

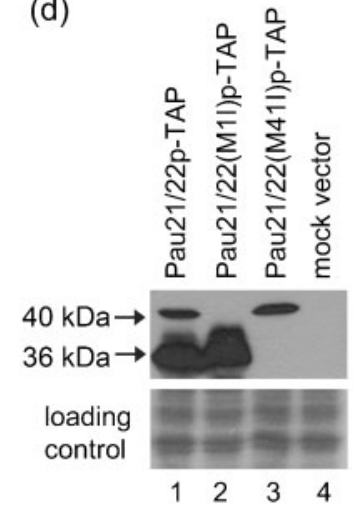

Fig. 4. Sequencing, cloning and expression of $P A U 7, P A U 9$ and PAU21/PAU22. (a) Schematic representation of ORFs for PAU7, $P A U 9$ and PAU21/PAU22. The dotted line indicates the position at which the nucleotide change will lead to the extension of the PAU7 ORF at the $3^{\prime}$ end, the PAU9 ORF at the $5^{\prime}$ end, or truncation of the PAU21/PAU22 ORF at the $5^{\prime}$ end to a size similar to that of other PAU ORFs. Arrows indicate the position and direction of oligonucleotides used for PCR amplification, sequencing and cloning. The number in front of the nucleotide indicates its position in the ORF. (b) Summary of the sequencing results. (c) Immunoblotting of cell lysates from cells expressing GFP-Pau fusions in a single-copy plasmid driven by the MET25 promoter. 'S' indicates that the PAU7 sequence was from strain S92; 'B' indicates that the PAU7 sequence was from strain BY4742. (d) Immunoblotting of cell lysates from cells expressing wild-type and two mutant Pau21/22p-TAP fusion proteins driven by their native promoters on a multicopy plasmid. Cells were grown under anaerobic conditions.

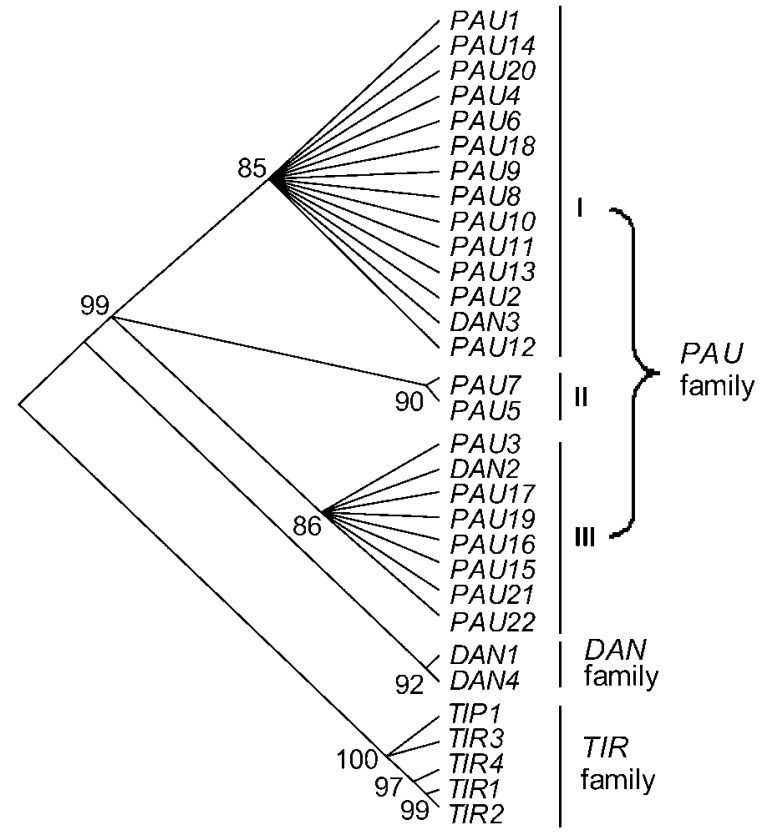

Fig. 5. Phylogenetic relationships of $P A U, D A N$ and $T I R$ genes. The phylogenetic tree (neighbour-joining method) was produced with MEGA 3.1. The bootstrap test of phylogenies was performed in 1000 replicates. The cut-off value was set at 85 .

the coding sequence $(85 \%)$, suggesting that flanking sequences have diverged faster than the coding sequences.

Duplicated genes can result from large-scale duplication, e.g. chromosomal or segmental duplication. In this type of duplication, the duplicated genes show high similarity in both the coding regions and their flanking regions. The duplication of the most subtelomeric $P A U$ genes might belong to this type. For example, PAU21 and PAU22 share $100 \%$ identity in the coding regions and $99 \%$ in the upstream regions (up to a few kilobases) and downstream regions (500 bp). The gene order in the PAU21 and PAU22 neighbourhood is PAU21-ERR1-HSP33-FDH1 and $P A U 22-E R R 2-H S P 32-F D H 2$, respectively. It is obvious that the gene pair of PAU21 and PAU22 is located within the segment that was duplicated between the right end of chromosome XV and the left end of chromosome XVI. The length of this duplication spans at least $11146 \mathrm{~kb}$. The other type of duplication is called retroposition (Zhang, 2003). This type occurs when an mRNA is retrotranscribed to cDNA, then inserted into the genome. Thus the promoter and termination sequences of the resulting duplicates usually have a different origin. Some of the internal $P A U$ genes or the other $P A U$ genes whose flanking sequences lack similarity might have originated through retroposition.

Motif searching using the YEASTRACT database (Teixeira et al., 2006) revealed some common features in the promoters of $P A U$ genes. All but one contain at least one copy of the Upc2p binding site (absent in PAU13) and the 
Table 3. Sequence similarity in 500 bp flanking regions between $P A U$ genes

The non-shadowed numbers represent the percentage identity between 500 bp sequences upstream of the start codon of $P A U$ genes; the shadowed numbers represent the percentage identity between 500 bp sequences downstream of the stop codon of PAU genes. -, No significant similarity.

\begin{tabular}{|c|c|c|c|c|c|c|c|c|c|c|c|c|c|c|c|c|c|c|c|c|c|c|c|c|}
\hline $\begin{array}{l}\text { Identity } \\
\text { (\%) }\end{array}$ & $\underset{丶}{\grave{\Sigma}}$ & 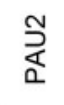 & 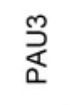 & 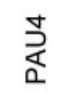 & 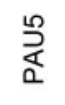 & 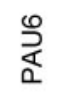 & 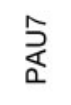 & 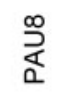 & $\frac{9}{2}$ & 은 & $\underset{\nwarrow}{\stackrel{5}{5}}$ & 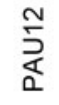 & $\underset{\frac{m}{L}}{\frac{m}{\alpha}}$ & 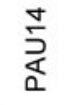 & 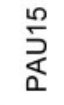 & $\frac{0}{\frac{6}{2}}$ & $\frac{5}{5}$ & 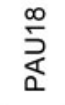 & $\frac{0}{5}$ & 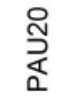 & 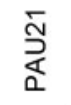 & 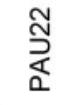 & $\underset{0}{z}$ & 孞 \\
\hline PAU1 & 100 & - & - & 92 & - & 93 & - & 94 & 91 & 94 & - & - & - & 99 & 86 & 95 & - & 93 & 74 & 95 & 74 & 74 & - & - \\
\hline PAU2 & - & 100 & - & - & - & - & - & - & - & - & - & - & - & - & - & - & - & - & - & - & - & - & - & - \\
\hline PAU3 & 92 & - & 100 & - & - & - & - & - & - & - & - & - & - & - & - & - & - & - & - & - & - & - & - & - \\
\hline PAU4 & 92 & - & 91 & 100 & - & 94 & - & 91 & 92 & 92 & - & - & - & 92 & - & 95 & - & 94 & 79 & 93 & 75 & 75 & - & - \\
\hline PAU5 & - & - & - & - & 100 & - & - & - & - & - & - & - & - & - & - & - & - & - & - & - & - & - & - & - \\
\hline PAU6 & 93 & - & 94 & 88 & - & 100 & - & 92 & 95 & 91 & - & - & - & 93 & - & 94 & - & 99 & 73 & 95 & 74 & 74 & - & - \\
\hline PAU7 & - & - & - & - & 79 & - & 100 & - & - & - & - & - & - & - & - & - & - & - & - & - & - & - & - & - \\
\hline PAU8 & 88 & - & 88 & 88 & - & 85 & - & 100 & 91 & 93 & - & - & - & 94 & - & 94 & - & 92 & 76 & 91 & 75 & 75 & - & - \\
\hline PAU9 & 90 & - & 95 & 90 & - & 92 & - & 85 & 100 & 94 & - & - & - & 91 & - & 92 & - & 94 & 77 & 94 & 73 & 73 & - & - \\
\hline PAU10 & 67 & - & 66 & 70 & - & 66 & - & 71 & 68 & 100 & - & - & - & 94 & - & 94 & - & 91 & 75 & 91 & 74 & 74 & - & - \\
\hline PAU11 & 92 & - & 90 & 91 & - & 90 & - & 88 & 89 & 68 & 100 & - & - & - & - & - & - & - & - & - & - & - & - & - \\
\hline PAU12 & - & - & - & - & - & - & - & - & - & - & - & 100 & - & - & - & - & - & - & - & - & - & - & - & 96 \\
\hline PAU13 & 87 & - & 85 & 86 & - & 84 & - & 84 & 86 & 67 & 85 & - & 100 & - & - & - & - & - & - & - & - & - & - & - \\
\hline PAU14 & 100 & - & 92 & 92 & - & 93 & - & 88 & 90 & 66 & 92 & - & 87 & 100 & - & 96 & - & 93 & 74 & 95 & 75 & 75 & - & - \\
\hline PAU15 & 93 & - & 90 & 92 & - & 89 & - & 90 & 88 & 67 & 96 & - & 86 & 93 & 100 & - & - & - & - & - & - & - & - & - \\
\hline PAU16 & 92 & - & 89 & 92 & - & 90 & - & 90 & 88 & 67 & 95 & - & 86 & 92 & 98 & 100 & - & 94 & 76 & 94 & 73 & 73 & - & - \\
\hline PAU17 & - & - & - & - & - & - & - & - & - & - & - & - & - & - & - & - & 100 & - & - & - & - & - & - & - \\
\hline PAU18 & 91 & - & 96 & 90 & - & 93 & - & 87 & 94 & 67 & 92 & - & 85 & 91 & 90 & 90 & - & 100 & 73 & 95 & 74 & 74 & - & - \\
\hline PAU19 & 84 & - & 80 & 82 & - & 81 & - & 80 & 80 & 68 & 82 & - & 86 & 84 & 83 & 83 & - & 79 & 100 & 76 & 94 & 94 & - & - \\
\hline PAU20 & 80 & - & 77 & 80 & - & 78 & - & 76 & 77 & 66 & 80 & - & 78 & 80 & 82 & 82 & - & 76 & 78 & 100 & 76 & 76 & - & - \\
\hline PAU21 & 84 & - & 80 & 83 & - & 81 & - & 81 & 80 & 68 & 82 & - & 85 & 84 & 83 & 83 & - & 80 & 95 & 77 & 100 & 99 & - & - \\
\hline PAU22 & 84 & - & 80 & 83 & - & 81 & - & 81 & 80 & 68 & 82 & - & 85 & 84 & 83 & 83 & - & 80 & 95 & 77 & 100 & 100 & - & - \\
\hline DAN2 & - & - & - & - & - & - & - & - & - & - & - & - & - & - & - & - & - & - & - & - & - & - & 100 & - \\
\hline DAN3 & - & - & - & - & - & - & - & - & - & - & - & - & - & - & - & - & - & - & - & - & - & - & - & 100 \\
\hline
\end{tabular}


Mot3p binding site (absent in PAU9) (Table 4). Upc2p induces transcription of sterol biosynthetic genes (Vik \& Rine, 2001) and of DAN/TIR genes (Abramova et al., 2001b) under hypoxic/anaerobic conditions. Its binding motif (TCGTTYAG) is also called an anaerobic response element (AR1) (Cohen et al., 2001). Mot3p is a transcription factor involved in repression of a subset of hypoxic genes by Roxlp, repression of several DAN/TIR genes during aerobic growth, and repression of ergosterol biosynthetic genes (Hongay et al., 2002; Sertil et al., 2003). Probably both Upc2p and Mot $3 p$ are also involved in the regulation of $P A U$ gene expression. The other common feature in the PAU promoters is they all have a TATA box in the region of -95 to -110 before the start codon. These findings are in agreement with a previous report that TATA-containing promoters are prevalent in subtelomeric regions, highly associated with response to stresses, and highly evolving (Basehoar et al., 2004).

\section{Differential expression of PAU genes}

Duplicated genes may gain novel functions through regulatory evolution. We therefore investigated whether the expression profiles of PAU genes are different. Given the high sequence similarity amongst the $P A U$ genes, which makes it impossible to detect signals from individual $P A U$ mRNAs due to cross-hybridization, we applied Western blot analyses to detect Pau protein levels. Five PAU genes, PAU3, PAU5, DAN2, PAU17 and PAU20, representing different subgroups and chromosomal localizations, were fused with a TAP tag just before the stop codon in their chromosomal loci. The expression of Pau5p-TAP, which has been previously reported (Luo \& van Vuuren, 2008), was used as a control. Western blot analysis revealed that like Pau5p-TAP, Dan2p-TAP and Pau20p-TAP were highly induced by low temperature and anaerobic conditions. Pau3p-TAP and Pau17p-TAP were not detected under any of the conditions tested (Fig. 6a). Since the stability of Pau proteins might differ, thus affecting steadystate levels, we measured the promoter activity by using the TAP tag as a reporter, replacing the PAU ORF with a TAP tag in the genome of BY4742. Expression was detected by Western blotting. As shown in Fig. 6(b), the basal constitutive expression of PAU5 and DAN2 was detected in cells grown in YPD. Treatment of yeast cells for $2 \mathrm{~h}$ with nitrogen starvation, carbohydrate starvation or growth in a

Table 4. Common DNA motifs in the PAU gene promoters

Each number represents the nucleotide position of the motifs upstream of the start codon of each $P A U$ gene; ' $c$ ' after the number indicates that the binding motif is on the complementary strand.

\begin{tabular}{|c|c|c|c|c|c|c|}
\hline \multirow[t]{2}{*}{$\begin{array}{l}\text { Gene } \\
\text { name }\end{array}$} & \multicolumn{2}{|c|}{$\begin{array}{l}\text { Anaerobic induction/Upc2p binding } \\
\text { sites }\end{array}$} & \multicolumn{3}{|c|}{ Aerobic repression/Mot3p binding sites } & \multirow{2}{*}{$\begin{array}{l}\text { TATA box } \\
\text { TATAAATA }\end{array}$} \\
\hline & TCGTATA & TCGTTYAG & TMGGAA & WAGGKA & CAGGYA & \\
\hline PAU1 & $-526 c$ & & $-723,-817 c$ & & & -100 \\
\hline PAU2 & $-215 c,-254 c$ & $-375 c$ & $-34 c$ & $-714 c,-538 c$ & & -95 \\
\hline$P A U 3$ & $-529 c$ & $-234,-419 c$ & -708 & & & -100 \\
\hline PAU6 & -530 & $-417 \mathrm{c}$ & $-718,-813 c$ & & & -101 \\
\hline PAU7 & $-980,-242 c$ & & $-247 c,-734 c$ & & & -108 \\
\hline PAU8 & $-523 c$ & -230 & $-916,-905$ & -901 & -362 & -100 \\
\hline PAU9 & $-776 c$ & $-469,-654 c$ & & & & -101 \\
\hline PAU10 & $-253 c$ & -434 & $-38 c,-390 c$ & $-861,-510$ & -364 & -109 \\
\hline PAU15 & $-525 c$ & -233 & $-928 c$ & -922 & -364 & -100 \\
\hline PAU16 & $-525 c$ & -233 & & & -364 & -100 \\
\hline PAU17 & $-964 c$ & $-211,-409 c$ & $-629 c$ & -339 & $-946 c$ & -107 \\
\hline PAU18 & $-543 c$ & -234 & -508 & & & -109 \\
\hline PAU19 & $-535 c$ & $-465,-416 c$ & & $-104,-259 c$ & & -100 \\
\hline PAU20 & $-526 c$ & $-463,-232$ & -721 & $-261 c$ & -369 & -100 \\
\hline PAU21 & $-418 \mathrm{c}$ & $-347,-298 c$ & -970 & $-141 c,-401 c$ & -245 & -100 \\
\hline PAU22 & $-418 \mathrm{c}$ & $-347,-298 c$ & -970 & $-141 c,-401 c$ & -245 & -100 \\
\hline DAN2 & $-263 c$ & -447 & $-76 c$ & $-353,-296$ & -554 & -111 \\
\hline DAN3 & $-262,-529 c$ & & -343 & $-353,-290$ & -874 & -101 \\
\hline
\end{tabular}


(a)

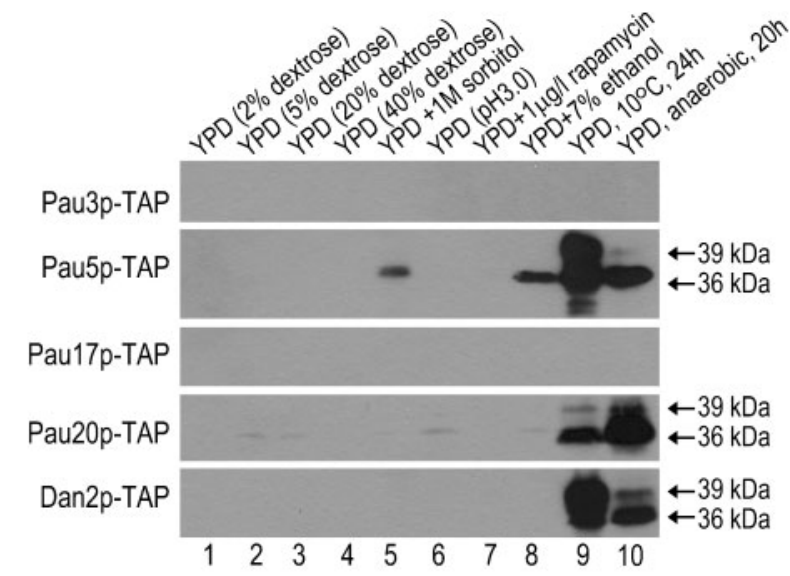

(b)

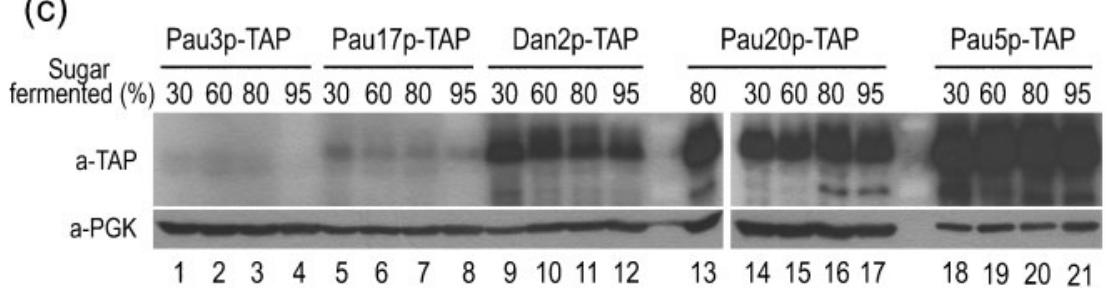

Fig. 6. Differential expression of $P A U$ genes. (a) Immunoblotting of cell lysates from strains LY5, LY6, LY7, LY 8 and LY9, which chromosomally encode Pau3p-TAP, Pau5p-TAP, Dan2p-TAP, Pau17p-TAP and Pau20p-TAP, respectively. Growth media and conditions were as indicated. (b) Immunoblotting of cell lysates from strains LY19, LY20, LY280, LY281 and LY282 (chromosomally encoding a TAP tag under the control of the native promoter of PAU3, PAU5, DAN2, PAU17 and PAU20, respectively). Aerobically grown exponential phase cells were collected, washed and resuspended in the media and grown under the conditions as indicated. YNB, yeast nitrogen base without ammonium sulphate and amino acids. Loading controls were visualized by immunoblotting the blots with anti-PGK mAbs. (c) Immunoblotting of cell lysates from wine yeast strains LY12-7, LY15-8, LY21-7, LY22-8 and LY23-8 (chromosomally encoding Pau3p-TAP, Pau5p-TAP, Dan2p-TAP, Pau17pTAP and Pau20p-TAP, respectively). Cells were collected at various stages during fermentation of Chardonnay grape must. Loading controls were visualized by immunoblotting with anti-PGK mAbs.

non-fermentative medium showed the least effect on the induction of the five $P A U$ genes. Under low temperature, the induction of TAP was observed in PAU5, PAU20 and DAN2, with much more induction of PAU5 and DAN2. Under anaerobic conditions, activity of the PAU3 pro- moter was weakly induced, while the activity of the PAU5, PAU20 and DAN2 promoters was dramatically increased. The induction of Pau-TAP fusion proteins in wine yeast strains was also investigated during alcoholic fermentation using Chardonnay grape must. The results (Fig. 6c) showed 
that Pau5p-TAP, Pau20p-TAP and Dan2p-TAP were largely induced at an early stage of fermentation and remained almost constant throughout the entire fermentation process. Pau17p-TAP was lightly induced, while almost no Pau3-TAP was observed. Obviously, these five $P A U$ genes responded differently to stress.

The repression of $P A U$ genes under aerobic conditions has been suggested to be caused by the telomere position effect (TPE) (Ai et al., 2002). To determine whether this is indeed the case, we studied the expression of the URA3 gene by growing Pau-TAP-tagged yeast strains on 5-fluoro-orotic acid (5-FOA) plates. In Pau-TAP-tagged strains, a copy of the URA3 gene with its native promoter is located in the region immediately downstream of the $P A U$ genes. If $U R A 3$ is expressed, it would make 5-FOA toxic and yeast cells would not grow (Boeke et al., 1984). Our results showed that as control, the strain BY4742 (ura3 $\Delta 0)$ grew well on the 5-FOA plate, while strains LY5 (PAU3-TAPURA3), LY6 (PAU5-TAP-URA3), LY7 (DAN2-TAPURA3), LY8 (PAU17-TAP-URA3) and LY9 (PAU20-TAP$U R A 3$ ) all failed to grow on the 5-FOA plate (data not shown), indicating that the native URA3 gene located in a similar position to the $P A U$ genes was expressed in all the PAU-TAP-URA3 strains. Therefore, repression of the subtelomeric PAU genes might not be due to TPE.

A hypothesis has been proposed elsewhere that subtelomeric $P A U$ genes are more weakly inducible than the internal ones, based on the expression of PAU4, PAU5 and PAU6 on the plasmid-borne copies of PAU-lacZ fusions (Rachidi et al., 2000). Our results (Fig. 6), however, indicate that PAU20, although located in the subtelomeric region, was highly induced by anaerobic conditions and weakly induced by low temperature. Therefore, gene position does not appear to correlate to expression under different conditions. Instead, we believe that the variation in promoter sequences, the number of copies and location of the stress-inducible elements and the repressor binding motifs (Table 4), as well as the $5^{\prime}$ and $3^{\prime}$ untranslated regions (UTRs), might be responsible for the differential expression of $P A U$ genes in response to stresses.

\section{Divergence in stability of Pau proteins}

To test whether the sequence divergence of Pau proteins affects their stability, we cloned all PAU ORFs into a $C E N$ based expression plasmid driven by the MET25 promoter. Pau-TAP fusion proteins were induced by growing cells in YNB medium without methionine. Western blot analysis showed that after $12 \mathrm{~h}$ induction, levels of individual Pau proteins varied, with the average amount of 120 and 122 aa Pau proteins being about eightfold more than that of 124 aa Pau proteins (Fig. 7a), suggesting that the latter are less stable. To confirm this, cycloheximide chase assays were performed for Paulp (120 aa) and Pau3p (124 aa). After protein synthesis was stopped by cycloheximide, Pau3-TAP degraded rapidly in YPD, with a half-life of less
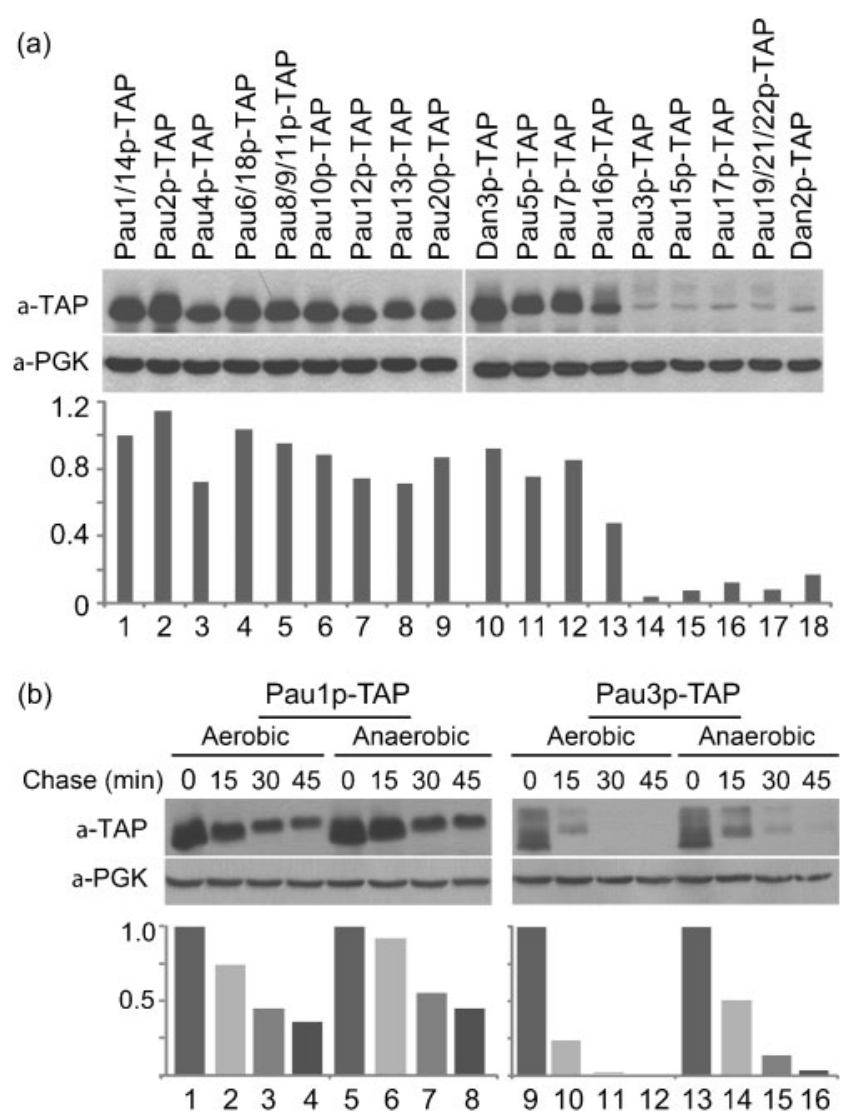

Fig. 7. Pau protein levels and their degradation. (a) Immunoblotting of cell extracts from exponentially growing cells that contained CEN-based plasmids encoding different Pau-TAP fusion proteins driven by the MET25 promoter. Cells were grown in YNB plus $2 \%$ glucose, ammonium sulphate and essential amino acids. (b) Immunoblotting of cell lysates from cycloheximidetreated cells. Cells expressing Pau1p-TAP and Pau3p-TAP under the control of the MET25 promoter in a CEN plasmid were aerobically or anaerobically grown to mid-exponential phase in YNB plus $2 \%$ glucose, ammonium sulphate and essential amino acids, exposed to cycloheximide, and chased under aerobic or anaerobic conditions for the times indicated. The blots were probed with anti-PGK antibodies as a reference. Charts at the bottom of (a) and (b) show the relative level of Pau5p-TAP normalized to the respective Pgk1p band signal. Signal quantification was performed with Image J (http://rsb.info.nih.gov/ij/).

than $15 \mathrm{~min}$, while the half-life of Pau1-TAP was $\sim 30 \mathrm{~min}$ (Fig. 7b). Anaerobic growth conditions slowed the degradation process of both proteins. In addition, the molecular size of Pau1-TAP and Pau3-TAP gradually increased during their degradation process, in agreement with the previous observations for Pau5p-TAP (Luo \& van Vuuren, 2008), which might be due to hyperphosphorylation. These results suggest that in addition to transcriptional regulation, yeast cells have evolved mechanisms to independently regulate the protein levels of the multiple $P A U$ genes. 
In conclusion, this study provides evidence that after duplication, paralogues of the multiple $P A U$ gene family have diverged at the levels of sequence, expression and protein stability. Although the function of Pau proteins has yet to be defined, the amplification and persistence of so many diversified $P A U$ genes might indicate that they have specific roles in the adaptation of yeasts to a variety of environmental stresses.

\section{ACKNOWLEDGEMENTS}

This work was supported by an Natural Sciences and Engineering Research Council (NSERC) grant (217271-04) to H. J. J.v.V. We thank Christopher Walkey for his critical reading of this manuscript.

\section{REFERENCES}

Abramova, N. E., Sertil, O., Mehta, S. \& Lowry, C. V. (2001a). Reciprocal regulation of anaerobic and aerobic cell wall mannoprotein gene expression in Saccharomyces cerevisiae. J Bacteriol 183, 28812887.

Abramova, N. E., Cohen, B. D., Sertil, O., Kapoor, R., Davies, K. J. \& Lowry, C. V. (2001b). Regulatory mechanisms controlling expression of the DAN/TIR mannoprotein genes during anaerobic remodelling of the cell wall in Saccharomyces cerevisiae. Genetics 157, 1169-1177.

Ai, W., Bertram, P. G., Tsang, C. K., Chan, T. F. \& Zheng, X. F. (2002). Regulation of subtelomeric silencing during stress response. Mol Cell 10, 1295-1305.

Alimardani, P., Regnacq, M., Moreau-Vauzelle, C., Ferreira, T., Rossignol, T., Blondin, B. \& Berges, T. (2004). SUT1-promoted sterol uptake involves the ABC transporter Aus1 and the mannoprotein Dan1 whose synergistic action is sufficient for this process. Biochem J 381, 195-202.

Altschul, S. F., Madden, T. L., Schäffer, A. A., Zhang, J., Zhang, Z., Miller, W. \& Lipman, D. J. (1997). Gapped BLAST and PSI-BLAST: a new generation of protein database search programs. Nucleic Acids Res 25, 3389-3402.

Ausubel, F. M., Brent, R., Kinston, R. E., Moore, D. D., Scidman, J. D., Smith, J. A. \& Struhl, K. (1999). Short Protocols in Molecular Biology, 4th edn. New York: Wiley.

Basehoar, A. D., Zanton, S. J. \& Pugh, B. F. (2004). Identification and distinct regulation of yeast TATA box-containing genes. Cell 116, 699-709.

Blandin, G., Durrens, P., Tekaia, F., Aigle, M., Bolotin-Fukuhara, M., Bon, E., Casaregola, S., de Montigny, J., Gaillardin, C. \& other authors (2000). Genomic exploration of the hemiascomycetous yeasts: 4 . The genome of Saccharomyces cerevisiae revisited. FEBS Lett 487, 31-36.

Boeke, J. D., LaCroute, F. \& Fink, G. R. (1984). A positive selection for mutants lacking orotidine-5'-phosphate decarboxylase activity in yeast: 5-fluoro-orotic acid resistance. Mol Gen Genet 197, 345-346.

Byrne, K. P. \& Wolfe, K. H. (2006). Visualizing syntenic relationships among the hemiascomycetes with the yeast gene order browser. Nucleic Acids Res 34, D452-D455.

Cohen, B. D., Sertil, O., Abramova, N. E., Davies, K. J. \& Lowry, C. V. (2001). Induction and repression of DAN1 and the family of anaerobic mannoprotein genes in Saccharomyces cerevisiae occurs through a complex array of regulatory sites. Nucleic Acids Res 29, 799808.
Davies, B. S. \& Rine, J. (2006). A role for sterol levels in oxygen sensing in Saccharomyces cerevisiae. Genetics 174, 191-201.

Despons, L., Wirth, B., Louis, V. L., Potier, S. \& Souciet, J. L. (2006). An evolutionary scenario for one of the largest yeast gene families. Trends Genet 22, 10-15.

Fabre, E., Muller, H., Therizols, P., Lafontaine, I., Dujon, B. \& Fairhead, C. (2005). Comparative genomics in hemiascomycete yeasts: evolution of sex, silencing, and subtelomeres. Mol Biol Evol 22, 856-873.

Goffeau, A., Barrell, B. G., Bussey, H., Davis, R. W., Dujon, B., Feldmann, H., Galibert, F., Hoheisel, J. D., Jacq, C. \& other authors (1996). Life with 6000 genes. Science 274, 546-567.

Gu, Z., Nicolae, D., Lu, H. H. \& Li, W. H. (2002). Rapid divergence in expression between duplicate genes inferred from microarray data. Trends Genet 18, 609-613.

Homma, T., Iwahashi, H. \& Komatsu, Y. (2003). Yeast gene expression during growth at low temperature. Cryobiology 46, 230-237.

Hongay, C., Jia, N., Bard, M. \& Winston, F. (2002). Mot3 is a transcriptional repressor of ergosterol biosynthetic genes and is required for normal vacuolar function in Saccharomyces cerevisiae. EMBO J 21, 4114-4124.

Kellis, M., Patterson, N., Endrizzi, M., Birren, B. \& Lander, E. S. (2003). Sequencing and comparison of yeast species to identify genes and regulatory elements. Nature 423, 241-254.

Kong, H., Landherr, L. L., Frohlich, M. W., Leebens-Mack, J., Ma, H. \& dePamphilis, C. W. (2007). Patterns of gene duplication in the plant SKP1 gene family in angiosperms: evidence for multiple mechanisms of rapid gene birth. Plant J 50, 873-885.

Kumar, S., Tamura, K. \& Nei, M. (2004). MEGA3: integrated software for Molecular Evolutionary Genetics Analysis and sequence alignment. Brief Bioinform 5, 150-163.

Luo, Z. \& van Vuuren, H. J. J. (2008). Stress-induced production, processing and stability of a seripauperin protein, Pau5p, in Saccharomyces cerevisiae. FEMS Yeast Res 8, 374-385.

Lynch, M. \& Conery, J. S. (2000). The evolutionary fate and consequences of duplicate genes. Science 290, 1151-1155.

Marks, V. D., Ho Sui, S. J., Erasmus, D., van der Merwe, G. K., Brumm, J., Wasserman, W. W., Bryan, J. \& van Vuuren, H. J. J. (2008). Dynamics of the yeast transcriptome during wine fermentation reveals a novel fermentation stress response. FEMS Yeast Res 8, 35-52.

Notredame, C., Higgins, D. G. \& Heringa, J. (2000). T-coffee: a novel method for fast and accurate multiple sequence alignment. J Mol Biol 302, 205-217.

Ohno, S. (1970). Evolution by Gene Duplication. New York: Springer. Pan, D. \& Zhang, L. (2008). Tandemly arrayed genes in vertebrate genomes. Comp Funct Genomics 545269.

Pryde, F. E., Gorham, H. C. \& Louis, E. J. (1997). Chromosome ends: all the same under their caps. Curr Opin Genet Dev 7, 822-828.

Rachidi, N., Martinez, M. J., Barre, P. \& Blondin, B. (2000). Saccharomyces cerevisiae PAU genes are induced by anaerobiosis. Mol Microbiol 35, 1421-1430.

Rossignol, T., Dulau, L., Julien, A. \& Blondin, B. (2003). Genome-wide monitoring of wine yeast gene expression during alcoholic fermentation. Yeast 20, 1369-1385.

Sahara, T., Goda, T. \& Ohgiya, S. (2002). Comprehensive expression analysis of time-dependent genetic responses in yeast cells to low temperature. J Biol Chem 277, 50015-50021.

Sertil, O., Kapoor, R., Cohen, B. D., Abramova, N. \& Lowry, C. V. (2003). Synergistic repression of anaerobic genes by Mot3 and Rox1 in Saccharomyces cerevisiae. Nucleic Acids Res 31, 5831-5837. 
Taylor, J. S. \& Raes, J. (2004). Duplication and divergence: the evolution of new genes and old ideas. Annu Rev Genet 38, 615-643.

Teixeira, M. C., Monteiro, P., Jain, P., Tenreiro, S. R., Fernandes, A. R., Mira, N. P., Alenquer, M., Freitas, A. T., Oliveira, A. L. \& Sá-Correia, I. (2006). The YEASTRACT database: a tool for the analysis of transcription regulatory associations in Saccharomyces cerevisiae. Nucleic Acids Res 34, D446-D451.

Vik, A. \& Rine, J. (2001). Upc2p and Ecm22p, dual regulators of sterol biosynthesis in Saccharomyces cerevisiae. Mol Cell Biol 21, 6395-6405.

Viswanathan, M., Muthukumar, G., Cong, Y. S. \& Lenard, J. (1994). Seripauperins of Saccharomyces cerevisiae: a new multigene family encoding serine-poor relatives of serine-rich proteins. Gene 148, 149-153.
Wirth, B., Louis, V. L., Potier, S., Souciet, J. L. \& Despons, L. (2005). Paleogenomics or the search for remnant duplicated copies of the yeast DUP240 gene family in intergenic areas. Mol Biol Evol 22, 17641771.

Wyrick, J. J., Holstege, F. C., Jennings, E. G., Causton, H. C., Shore, D., Grunstein, M., Lander, E. S. \& Young, R. A. (1999). Chromosomal landscape of nucleosome-dependent gene expression and silencing in yeast. Nature 402, 418-421.

Zhang, J. (2003). Evolution by gene duplication: an update. Trends Ecol Evol 18, 292-298.

Edited by: K. Kuchler 